\title{
PENGARUH PENAMBAHAN SEMEN PORTLAND DAN SERUK BATU BATA TERHADAP NILAI DAYA DUKUNG TANAH GAMBUT
}

\author{
Reyana Claudia Valentin ${ }^{1}$, Mohammad Ikhwan Yani ${ }^{3}$ dan Suradji gandi ${ }^{3}$ \\ ${ }^{123}$ Program Studi Teknik Sipil, Fakultas Teknik, Universitas Palangka Raya \\ E-mail: reyanaclaudia@gmail.com¹,m.ikhwanyani@eng.upr.ac.id²/ \\ HP.+6282151650640 ${ }^{1}$, dan suradjigandi_ir@jts.upr.ac.id ${ }^{3}$
}

\begin{abstract}
ABSTRAK
Umumnya sebagian besar daerah dijalan mahir mahar kota Palangka Raya Provinsi Kalimantan Tengah dipenuhi oleh tanah gambut dengan penyebaran yang cukup luas. Luas area tanah gambut yang cukup luas merupakan kendala dalam pembangunan infastruktur. Penelitian ini bertujuan untuk menstabilisasi tanah asli mengunakan bahan aditif berupa semen portland dan serbuk batu bata. Berdasarkan hasil pengujian sifat fisik tanah asli didapat nilai, kadar air $(w)=513,15 \%$; berat isi kering $\left(\gamma_{\mathrm{d}}\right)=1,27 \mathrm{~g} / \mathrm{cm}^{3}$; berat jenis $(G s)=1,50$; kadar serat $=46,78 \%$; analisis saringan $200=16,48 \%$. Hasil pengujian sifat mekanik tanah asli menunjukan bahwa nilai kadar air optimum $(O M C)=$ $88,28 \%$; berat isi kering $\left(\gamma_{\mathrm{d} \text { max }}\right)=0,45 \mathrm{~g} / \mathrm{cm}^{3}$; dan nilai CBR tanah asli adalah $1,35 \%$. Campuran semen portland, dan serbuk batu bata berdampak pada meningkatnya nilai CBR. Penambahan variasi $5 \%, 7,5 \%$, dan $10 \%$ pada setiap campuran menghasilkan nilai CBRrencana yang meningkat yaitu semen portland $2,15 \% ; 2,40 \% ; 2,60 \%$ dan pada serbuk batu bata $1,60 \% ; 1,80 \% ; 2,25 \%$. Nilai CBR terbesar terjadi pada penambahan semen portland $10 \%$ yaitu $2,60 \%$ meningkat $92,59 \%$ dari nilai CBR tanah asli dan nilai DDT terbesar terjadi dipenambahan semen portland $10 \%$ yaitu sebesar 3,50 meningkat $54,85 \%$ dari nilai DDT tanah asli.
\end{abstract}

Kata Kunci: Tanah Gambut, Semen Portland, Serbuk Batu Bata, CBR

\section{ABSTRACT}

Generally, most of the areas on the Mahir Mahar street, Palangka Raya city, Central Borneo Province are filled with peat soils with a fairly wide distribution. The large area of peat land is an obstacle in infrastructure development. This study aims to stabilize the original soil using additional materials in the form of Portland cement and brick powder. Based on the test results of the physical properties of the original soil, the water content $(\mathrm{w})=513.15 \%$; dry bulk weight $(\gamma \mathrm{d})=1.27 \mathrm{~g} / \mathrm{cm} 3$; specific gravity $(\mathrm{Gs})=1.50$; fiber content $=46.78 \%$; sieve analysis $200=$ $16.48 \%$. The results of testing the mechanical properties of the original soil showed that the optimum moisture content $(\mathrm{OMC})=88.28 \%$; dry bulk weight $\left(\gamma \_\mathrm{dmax}\right)=0.45 \mathrm{~g} / \mathrm{cm} 3$; and the original soil CBR value was $1.35 \%$. The mixture of Portland cement and brick powder has an impact on increasing the CBR value. The addition of variations of 5\%,7.5\%, and $10 \%$ in each mixture resulted in an increased CBR plan value, namely Portland cement $2.15 \% ; 2.40 \% ; 2.60 \%$ and $1.60 \%$ for brick powder; $1.80 \% ; 2.25 \%$. The largest CBR value occurred in the addition of $10 \%$ Portland cement, namely $2.60 \%$, an increase of $92.59 \%$ from the CBR value of the original soil and the greatest DDT value occurred in the addition of $10 \%$ portland cement, namely 3.50 or an increase of $54.85 \%$ from the original soil DDT value.

Keyword: Peat Soil, Portland Cement, Brick Powder, CBR 


\section{Latar Belakang}

\section{PENDAHULUAN}

Tanah gambut atau yang lebih dikenal sebagai peat soil adalah tanah yang memiliki kandunganb organik lebih dari $75 \%$ hal ini disebabkan oleh pelapukan tumbuhtumbuhan yang terjadi di dataran rendah selalu digenangi air. Dijalan Mahir Mahar, Kota Palangka Raya, Kalimanatan Tengah masih banyak lokasi yang memiliki area tanah gambut yang cukup luas dan merupakan kendala dalam pengembangan infastruktur suatu wilayah salah satu adalah pembangunan sarana transportasi. Hal ini disebabkan tanah gambut merupakan tanah yang sangat lunak dengan daya dukung sangat rendah dan mempunyai sifat mudah mampat jika terdapat beban yang berkerja diatasnya. Salah satu parameter yang menjadi tolak ukur dalam penentuan kemampuan tanah yaitu nilai daya dukung tanah adalah berupa nilai California Bearing Ratio (CBR). Untuk memperbaiki sifat tanah gambut dalam bidang teknik dilakukan dengan cara stabilisasi tanah. Stabilisasi tanah pada prinsip untuk mengubah atau memperbaiki sifat sifat teknik agar memenuhi syarat teknis tertentu. Dalam penelitian ini, stabilisasi tanah gambut dilakukan secara kimiawi dengan menggunakan campuran semen portland dan serbuk batu bata sebagai zat aditif. Penelitian ini diharapkan dapat memberi solusi dan mengatasi masalah pada tanah gambut serta dapat menstabilkan atau mengurangi sifat buruk pada tanah gambut.

\section{Tujuan Penelitian}

Adapun tujuan dari penelitian ini:

1. Mengetahui karakteristik sifat sifat tanah gambut di Jalan Mahir Mahar (Lingkar Luar) Palangka Raya, Kalimantan Tengah.

2. Mengetahui perubahan CBR dan perubahan kepadatan maksimum dari nilai CBR setelah distabilisasi dengan campuran semen portland dan serbuk batu bata.

3. Mengetahui pengaruh semen portland dan serbuk batu bata yang digunakan untuk meningkatkan daya dukung tanah.

\section{Tanah Gambut}

\section{TINJAUAN PUSTAKA}

Tanah Gambut merupakan jenis tanah organik yang terbentuk dari akumulasi sisa-sisa tumbuhan yang membusuk dan memiliki kandungan organiknya tinggi. Pada sumber lain dinyatakan bahwa tanah gambut merupakan material organic yang berasal dari tumbuhan dan terbentuk dalam tanah basah yang berubah secara kimia akibat perubahan cuaca dan kondisi topografi ( Dhowian, 1980).

Tabel 1. Batasan Berat Jenis Tanah

\begin{tabular}{lc}
\hline \multicolumn{1}{c}{ Tipe Tanah } & Berat Jenis ( Gs) \\
\hline Kerikil & $2,65-2,68$ \\
Pasir & $2,65-2,68$ \\
Lanau Anorganik & $2,65-2,68$ \\
Lempung Organik & $2,58-265$ \\
Lempung Anorganik & $2,68-2,75$ \\
Humus & 1,35 \\
Gambut & $1,25-1,80$ \\
\hline
\end{tabular}

Sumber : Hardiayatmo (1992) 


\section{Semen Portland}

Semen adalah material yang mempunyai sifat-sifat adhesif dan kohesif sebagai perekat yang mengikat fragmen-fragmen mineral menjadi suatu kesatuan yang kompak. Perekat inilah yang menimbulkan reaksi memadat dan membentuk massa yang keras. Semen dikelompokkan kedalam 2 (dua) jenis yaitu semen hidrolis dan semen non-hidrolis. Semen hidrolis adalah suatu bahan pengikat yang mengeras jika bereaksi dengan air serta menghasilkan produk yang tahan air, sedangkan semen non-hidrolis adalah suatu bahan pengikat yang bila dicampur dengan air menghasilkan produk yang dapat mengeras setelah bereaksi dengan karbondioksida, bukan dengan air.

\section{Serbuk batu bata}

Salah satu bahan material sebagai bahan pembuat dinding. Batu bata terbuat dari tanah liat yang dibakar sampai berwarna kemerah-merahan dan serbuk batu bata adalah batu bata yang dihaluskan dan dalam penelitian batu bata yang digunakn didapat dari sisa banggunan Batu bata yang digunakan dalam penelitian ini berasal dari Palangka Raya.

\section{Stabilitas Tanah}

Stabilitas tanah adalah usaha untuk memperbaiki sifat-sifat tanah dengan menambahkan sesuatu pada tanah tersebut, agar dapat menaikkan kekuatan tanah dan mempertahankan kekuatan geser. Menurut Bowles (1986), Stabilitas tanah terdiri dari tindakan berikut:

a. menambah material yang tidak aktif sehingga meningkatkan kohesi atau tahan geser.

b. Menambah material yang menyebabkan perubahan kimiawi dan fisik dari material tanah.

c. Menambah kerapatan tanah

d. Mengganti tanah-tanah yang buruk

e. Menurunkan muka air tanah ( dewatering )

\section{Pemadatan Tanah}

Pemadatan adalah proses naiknya kerapatan tanah dengan memperkecil jarak antar partikel sehingga terjadi reduksi volume udara. Tingkat pemadatan diukur dari berat volume kering yang dipadatkan. Berat volume tanah basah dan kadar air Usaha pemadatan yang sama, berat volume kering dari tanah akan naik bila kadar air dalam tanah (pada saat dipadatkan) meningkat (Prihatono, 2011). Uji pemadatan biasanya dilakukan untuk menentukan hubungan kadar air dan berat volume serta untuk memperbaiki tanah agar sesuai persyaratan kepadatan. Proctor (1933) dalam Hardiyatmo (2002) menyatakan bahwa ada hubungan yang pasti antara kadar air dan berat volume kering tanah padat.

\section{Uji CBR (California Bearing Ratio)}

Pengujian CBR (California Bearing Ratio) adalah perbandingan antara beban penetrasi suatu lapisan tanah atau perkerasan terhadap bahan standar dengan kedalaman dan kecepatan penetrasi yang sama. Metode ini dikembangkan oleh California State Highway Departement sebagai cara untuk menilai kekuatan tanah dasar jalan. Nilai CBR adalah nilai yang menyatakan kualitas tanah dasar yang dibandingkan dengan beban standar berupa batu pecah yang mempunyai nilai CBR $100 \%$ dalam memikul beban. Sedangkan, 
nilai CBR yang dapat digunakan untuk menentukan tebal lapisan perkerasan diperlukan di atas lapisan mempunyai nilai CBR tertentu.

Tabel 2. Klasifikasi Nilai CBR Tanah

\begin{tabular}{ccc}
\hline CBR $(\%)$ & Tingkatan Umum & Kegunaan \\
\hline $0-3$ & Very poor & Subgrade \\
$3-7$ & Poor to fair & Subgrade \\
$7-20$ & Fair & Subbase \\
$20-50$ & Good & Base or subbase \\
$>50$ & Excellent & Base \\
\hline
\end{tabular}

Sumber: Bowles, 1991.

\section{METODE PENELITIAN}

\section{Lokasi Penelitian}

Penelitian ini menggunakan sampel tanah gambut yang berasal dari jalan Mahir Mahar, Palangka Raya, Kalimantan Tengah. Studi penelitian ini dilakukan di Laboratorium Mekanika Tanah Jurusan/Program Studi Teknik Sipil Fakultas Teknik Universitas Palangka Raya.

\section{Metode Pengambilan Data}

Pada penelitian ini pengambilan sampel tanah gambut didapatkan dari jalan mahir mahar, Palangka Raya, Kalimantan Tengah. Ada dua sampel tanah yang diambil yaitu sampel tanah asli (undisturbed) yaitu tanah yang tidak mengalami perubahan sifat mekaniknya dan sampel tanah terganggu (disturbed)yaitu tanah yang telah terjamah atau sudah tidak alami lagi yang telah terganggu oleh lingkungan luar.

\section{Perencanaan Campuran}

Metode pencampuran tanah asli:

a) Sampel tanah yang telah ditumbuk (butir aslinya tidak pecah) dan lolos saringan No. $4(4,75 \mathrm{~mm})$ lalu dicampur dengan semen portland dan serbuk batu bata dengan varian campuran $5 \%, 7,5 \%, 10 \%$

b) Lalu dilakukan pemeraman selama 7 hari untuk pengujian pemadatan dan pengujian CBR.

c) Setelah didapatkan kadar air optimal dari pemadatan lalu dilakukan pengujian CBR.

d) Setelah didapat variasi yang paling optimum, lalu dilakukan analisis data dan pengolahan data. 
JURNAL KACAPURI

JURNAL KEILMUAN TEKNIK SIPIL

Volume 4 Nomor 1 Edisi Juni 2021

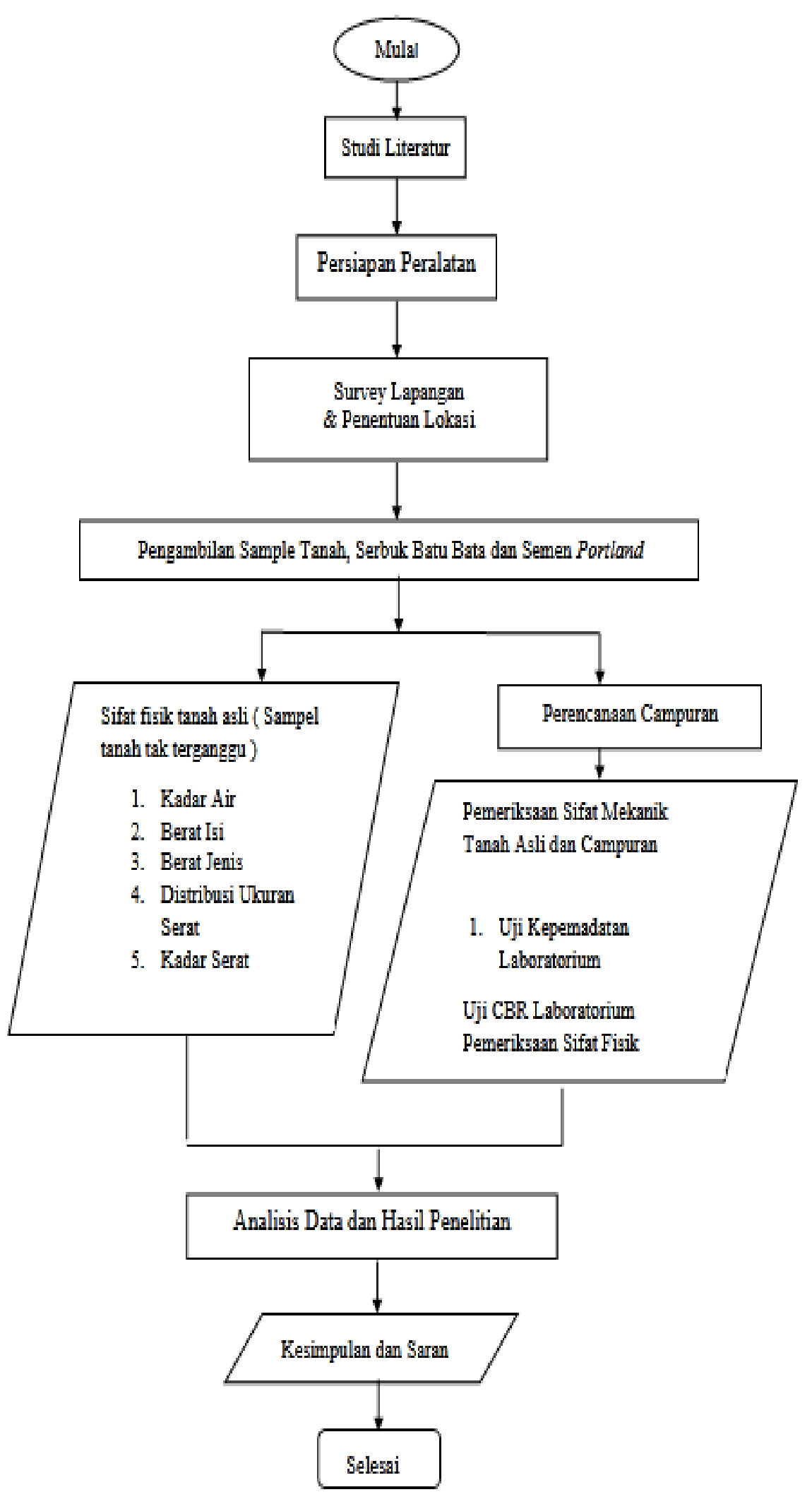

Gambar 1. Bagan Alir Penyusunan Penelitian 


\section{HASIL DAN PEMBAHASAN}

Pengujian yang dilakukan dilaboratorium meliputi kadar air, berat isi, berat jenis , kadar serat dan Distribusi Serat. Pengujian ini di lakukan di Laboratorium Mekanika Tanah Fakultas Teknik Universitas Palangka Raya. Penelitian ini diharapkan dapat memberikan gambaran mengenai karakter istik tanah, yang meliputi sifat fisik dan mekanik.

\section{Hasil Pengujian Sifat-Sifat Fisik Tanah}

Tabel 3.Hasil Pemeriksaan Sifat Fisik Tanah

\begin{tabular}{clc}
\hline No. & \multicolumn{1}{c}{ Jenis Pemeriksaan } & $\begin{array}{c}\text { Hasil Pengujian } \\
\text { Rata - rata }\end{array}$ \\
\hline 1. & Kadar Air (Water Content) \% & 513,15 \\
2. & Berat Isi (Density Test) gr/cm & 1,27 \\
3. & Berat Jenis (Specific Gravity) & 1,50 \\
4. & Porositas (\%) & 87 \\
5. & Kadar Serat (fiber content) $\%$ & 46,78 \\
6. & Distribusi Serat ( \%) & 56,04 \\
& -Kasar & 65,42 \\
& - medium & 85,52 \\
\hline
\end{tabular}

Dari sistem klasifikasi tanah menurut ASTMD4427-92, Tanah di jalan mahir mahar termasuk kedalam kategori moderate absorbent karena memiliki kadar air yang cukup tinggi dan berdasarkan kadar serat termasuk kedalam kategori hemic peat karena memiliki kandungan sekitar $33 \%-67 \%$.

\section{Hasil Pengujian Sifat-Sifat Mekanik Tanah}

\section{Uji Pemadatan}

Pengujian pemadatan tanah dilakukandengan cara pemadatan metode modified yang menggunakan standar ASTM D 698. Pengujian ini dilakukan untuk mendapatkan kadar air optimum dan berat volume kering tanah maksimum yang digunakan sebagai kadar air pada pengujian CBR.

Tabel 4.Rekapitulasi Hasil Pengujian Pemadatan Laboratorium

\begin{tabular}{cccc}
\hline Variasi Campuran & $\begin{array}{c}\text { Waktu } \\
\text { Pemeraman }\end{array}$ & $\begin{array}{c}\text { Kadar Air } \\
\text { Optimum } \\
(\%)\end{array}$ & $\begin{array}{c}\text { Kepadatan } \\
\text { Maksimum } \\
\left(\mathrm{g} / \mathrm{cm}^{3}\right)\end{array}$ \\
\hline Tanah Asli & 0 Hari & 88,28 & 0,45 \\
Tanah Asli + Serbuk Batu Bata 5\% & 7 Hari & 73,42 & 0,51 \\
Tanah Asli + Serbuk Batu Bata 7,5 \% & 7 Hari & 74,48 & 0,53 \\
Tanah Asli + Serbuk Batu Bata 10 \% & 7 Hari & 77,29 & 0,55 \\
Tanah Asli + Semen Portland 5\% & 7 Hari & 71,53 & 0,52 \\
Tanah Asli + Semen Portland 7,5\% & 7 Hari & 73,55 & 0,54 \\
Tanah Asli + Semen Portland 10 \% & 7 Hari & 75,36 & 0,56 \\
\hline
\end{tabular}


Pada tabel di atas menunjukan bahwa kadar air optimum pada tanah asli adalah sebesar $88,28 \%$ dengan kepadatan maksimum $0,45 \mathrm{~g} / \mathrm{cm}^{3}$, yang berarti kadar air pada tanah asli adalah yang paling terbesar sedangkan pada kepadatan maksimum yang paling terendah. Sedangkan pada setiap penambahan variasi kadar campuran semen portland dan serbuk batu bata terlihat berdampak baik pada nilai kepadatan maksimum pada setiap penambahan kadar variasinya, yang membuat kepadatan maksimum tanah meningkat seiring meningkatnya kadar air optimum juga. Peningkatan maksimal terjadi dipenambahan semen portland $10 \%$, dengan kepadatan maksimum mencapai $0,56 \mathrm{~g} / \mathrm{cm}^{3}$ dan kadar air optimum sebesar 75,36\%.

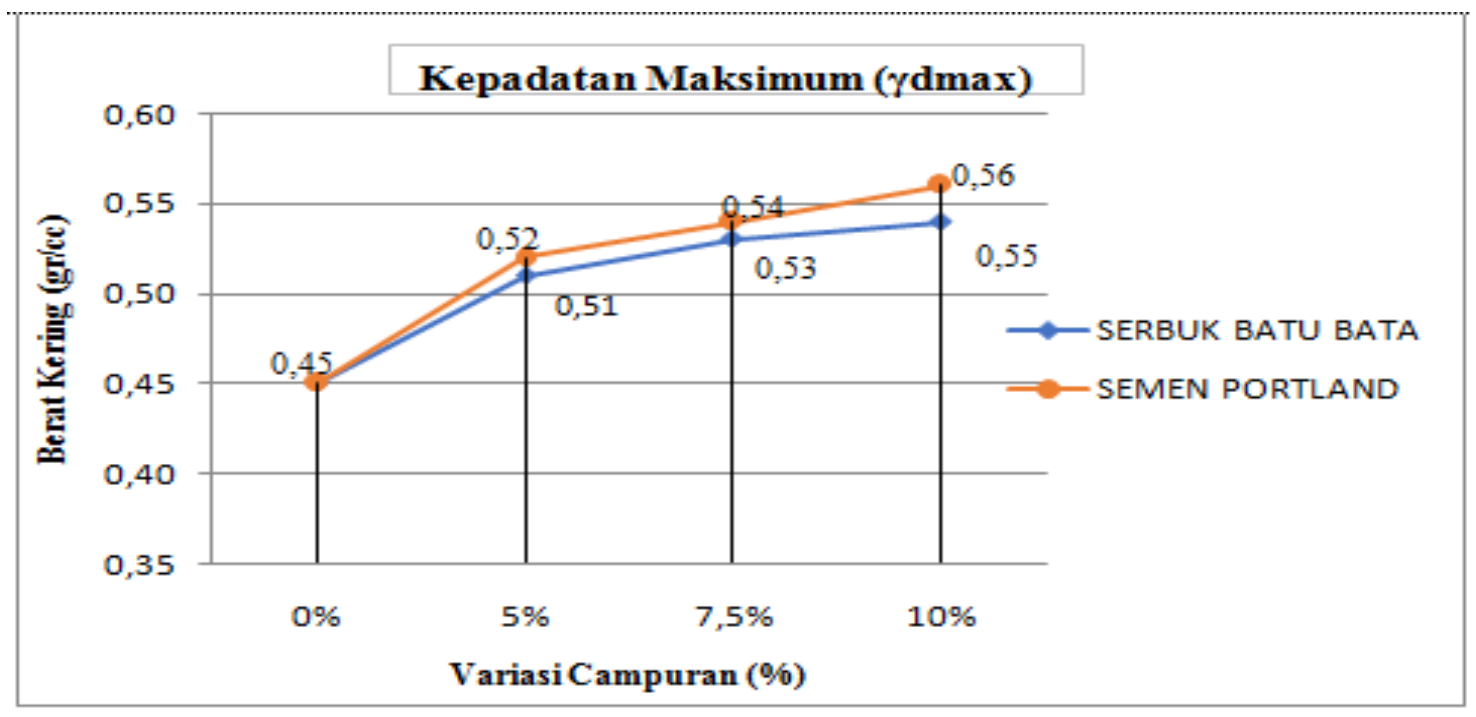

Gambar 2.Grafik Hasil Pengujian Pemadatan Laboratorium

Dapat dilihat pada gambar grafik di atas bahwa kepadatan maksimum tanah asli adalah sebesar $0,45 \mathrm{~g} / \mathrm{cm}^{3}$. Setelah dilakukan penambahan variasi kadar campuran terjadi kenaikan nilai dari kepadatan maksimum tanah asli. Pada penambahan serbuk batu bata kenaikan tertinggi terjadi pada varian $10 \%$ dengan kepadatan maksimum tanah naik sebesar $0,55 \mathrm{~g} / \mathrm{cm}^{3}$ meningkat sebesar $13,33 \%$ dari berat maksimum tanah asli dan pada penambahan semen portland tertinggi terjadi pada varian $10 \%$ dengan kepadatan maksimum tanah naik sebesar $0,56 \mathrm{~g} / \mathrm{cm}^{3}$ meningkat sebesar $24,44 \%$.

\section{Uji CBR}

Pengujian ini dimaksudkan untuk menentukan nilai CBR dengan mengetahui kuat hambatan campuran tanah dengan semen portland dan serbuk batu bata terhadap penetrasi kadar air optimum dengan waktu pemeraman 7 hari dengan variasi campuran $5 \%, 7,5 \%$ dan $10 \%$. 
Tabel 5. Rekapitulasi Hasil Pengujian CBR Laboratorium

\begin{tabular}{cccc}
\hline Variasi Campuran & $\begin{array}{c}\text { Waktu } \\
\text { Pemeraman }\end{array}$ & $\begin{array}{c}\text { Kadar Air } \\
\text { Optimum } \\
(\%)\end{array}$ & $\begin{array}{c}\text { Kepadatan } \\
\text { Maksimum } \\
\left(\mathrm{g} / \mathrm{cm}^{3}\right)\end{array}$ \\
\hline Tanah Asli & 0 Hari & 0,45 & $1,35 \%$ \\
Tanah Asli + Serbuk Batu Bata 5 \% & 7 Hari & 0,51 & $1,60 \%$ \\
Tanah Asli + Serbuk Batu Bata 7,5\% & 7 Hari & 0,53 & $1,80 \%$ \\
Tanah Asli + Serbuk Batu Bata 10 \% & 7 Hari & 0,55 & $2,25 \%$ \\
Tanah Asli + Semen Portland 5\% & 7 Hari & 0,52 & $2,15 \%$ \\
Tanah Asli + Semen Portland 7,5 \% & 7 Hari & 0,54 & $2,40 \%$ \\
Tanah Asli + Semen Portland 10\% & 7 Hari & 0,56 & $2,60 \%$ \\
\hline
\end{tabular}

Pada tabel di atas menunjukan bahwa nilai CBR pada tanah asli cukup rendah yaitu $1,35 \%$. Sedangkan pada setiap penambahan variasi kadar campuran semen portland dan serbuk batu bata berdampak terhadap naiknya nilai CBR pada setiap penambahan kadar variasinya. Peningkatan maksimal terjadi dipenambahan semen portland $10 \%$, dengan nilai CBR maksimum mencapai 2,60\%.

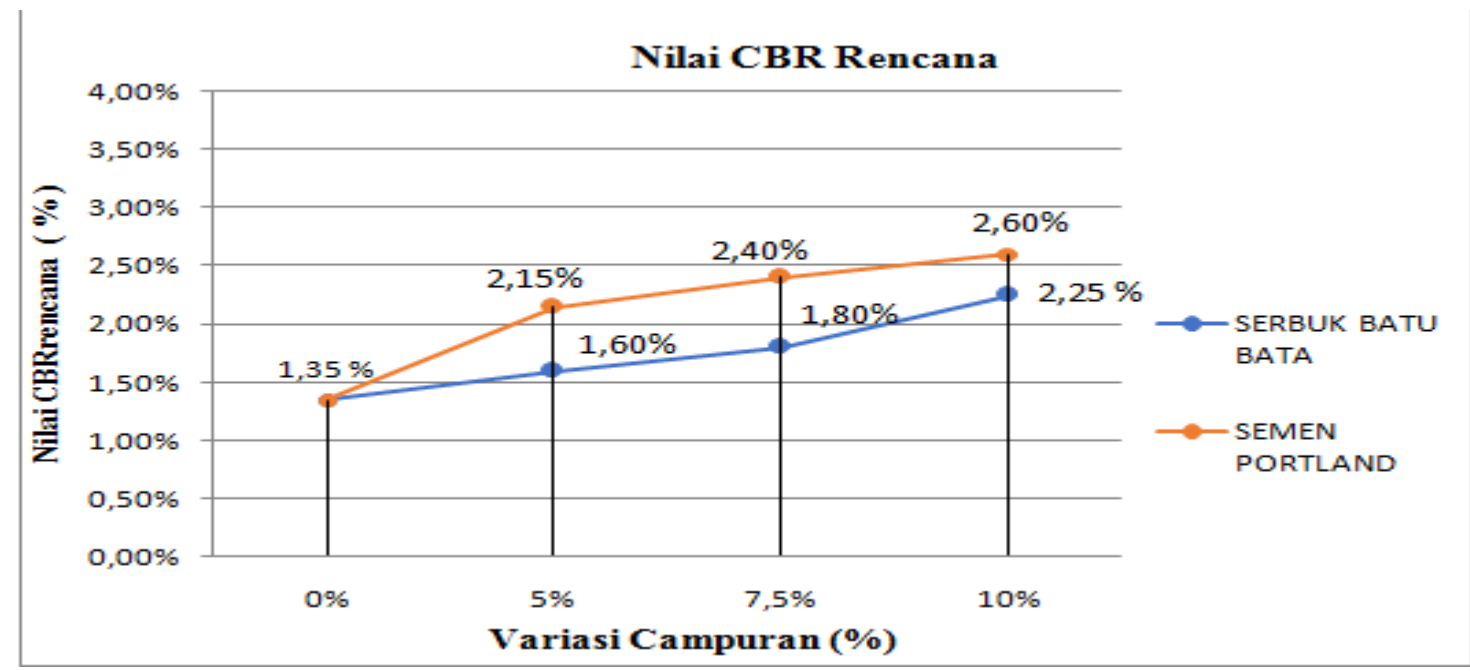

Gambar 3.Grafik Hasil Pengujian CBR Laboratorium

Dapat dilihat pada gambar grafik di atas dapat disimpulkan bahwa nilai CBR tanah asli cukup rendah yaitu $1,35 \%$. Sedangkan penambahan semen portland dan serbuk batu bata dengan pemeraman 7 hari, meningkatkan nilai CBR disetiap campuran. Pada campuran serbuk batu bata dengan varian $10 \%$ nilai CBR naik 2,25\% meningkat sebesar 66,67 \% dari tanah asli dan pada campuran semen portland dengan variasi tertinggi $10 \%$ nilai CBR $2,60 \%$ meningkat sebesar $92,59 \%$ dari tanah asli.

\section{Hubungan Daya Dukung Tanah dengan CBR Rencana}

Daya dukung tanah dasar (DDT) merupakan salah satu parameter yang digunakan dalam nonogram penetapan indeks tebal perkerasan (ITP). Nilai daya dukung tanah dasar didapat dari hari grafik kolerasi CBR tanah dasar terhadap DDT, secara analitis nilai DDT dengan menggunakan persamaan berikut (Sukirman,1999). 
$\mathrm{DDT}=4,3 \log \mathrm{CBR}+1,7$

Keterangan:

DDT: daya dukung tanah dasar

CBR: nilai CBR tanah dasar

Dengan Maka didapat nilai DDT sebagai berikut:

$\operatorname{DDT}=4,3 \times \log (2,60)+1,7=3,50$

Tabel 6.Rekapitulasi Hasil Hubungan Daya Dukung Tanah Dasar dengan CBRRencana

\begin{tabular}{cccc}
\hline Variasi Campuran & $\begin{array}{c}\text { Waktu } \\
\text { Pemeraman }\end{array}$ & $\begin{array}{c}\text { Nilai } \\
\text { CBR } \\
\text { RENCANA } \\
(\%)\end{array}$ & $\begin{array}{c}\text { Nilai Daya } \\
\text { Dukung } \\
\text { Tanah Dasar }\end{array}$ \\
\hline Tanah Asli & 0 Hari & 1,35 & 2,26 \\
Tanah Asli + Serbuk Batu Bata 5\% & 7 Hari & 1,60 & 2,57 \\
Tanah Asli + Serbuk Batu Bata 7,5\% & 7 Hari & 1,80 & 2,80 \\
Tanah Asli + Serbuk Batu Bata 10\% & 7 Hari & 2,25 & 3,21 \\
Tanah Asli + Semen Portland 5\% & 7 Hari & 2,15 & 3,13 \\
Tanah Asli + Semen Portland 7,5\% & 7 Hari & 2,40 & 3,33 \\
Tanah Asli + Semen Portland 10\% & 7 Hari & 2,60 & 3,50 \\
\hline
\end{tabular}

Dari tabel di atas dapat dilihat bahwa DDT tanah asli adalah sebesar 2,26. Dengan penambahan semen portland dan serbuk batu bata nilai DDT meningkat di setiap penambahan campurannya, pada campuran serbuk batu bata dengan varian tertinggi $10 \%$ nilai DDT meningkat sebesar 3,21 meningkat sebesar 42,03\% dari nilai DDT tanah asli,pada campuran semen portland dengan varian tertinggi $10 \%$ nilai DDT meningkat sebesar 3,50 meningkat sebesar 54,85\% dari nilai DDT tanah asli.

\section{Kesimpulan}

\section{PENUTUP}

Berdasarkan penelitian yang telah dilakukan, maka dapat diambil kesimpulan sebagai berikut:

1. Hasil pengujian sifat fisik tanah asli didapat nilai, kadar air $(w)=513,15 \%$; berat isi kering $\left(\gamma_{\mathrm{d}}\right)=1,27 \mathrm{~g} / \mathrm{cm}^{3}$; berat jenis $(G s)=1,50$; Analisis saringan persentase lolos saringan No.200 $=16,48 \%$. Menurut ASTM tanah gambut di jalan mahir mahar tersebut diklasifikasikan kategori moderate absorbent dan kategori hemic peat.

2. Hasil uji sifat mekanik tanah untuk pemadatan laboratorium untuk sampel tanah asli, nilai kadar air optimum $(O M C)=88,28 \%$; berat isi kering $\left(\gamma_{\mathrm{d} \max }\right)=0,45 \mathrm{~g} / \mathrm{cm}^{3}$; dan nilai CBR tanah asli adalah $1,35 \%$.

3. Campuran semen portland dan serbuk batu bata yang dicampurkan dengan tanah asli berdampak pada meningkatnya nilai CBR, dengan variasi campuran yang berbedabeda dan waktu pemeraman selama 7 hari. Setelah ditambah dengan variasi campuran $5 \%, 7,5 \%$, dan $10 \%$ didapat nilai CBR RENCANA dengan nilai terbesar pada campuran semen portland $10 \%$ yaitu sebesar $2,60 \%$ meningkat $92,59 \%$ dari nilai CBR tanah asli. 
4. Dari hasil nilai CBR RENCANA yang didapat, dapat dihitung nilai DDT dari hubungan antara nilai daya dukung tanah dasar dengan CBR RENCANA. Nilai DDT tanah asli adalah sebesar 2,26 dengan penambahan semen portland dan serbuk batu bata DDT meningkat sebesar 2,57, 2,80, 3,21, 3,13, 3,33, 3,50. Nilai DDT terbesar terjadi dipenambahan semen portland $10 \%$ yaitu sebesar 3,50 meningkat $54,85 \%$ dari nilai DDT tanah asli.

\section{Saran}

Berdasarkan hasil dari penelitian dan analisis data yang dilakukan, maka disarankan halhal sebagai berikut:

1. Untuk penelitian selanjutnya, semen portland dan serbuk batu bata yang digunakan sebagai bahan stabilisasi tanah harus diketahui jenis variasi campuran untuk memperoleh hasil optimal.

2. Perlunya pertimbangan waktu pemeraman tanah gambut dengan campuran semen portland dan serbuk batu bata sebagai bahan stabilisasi.

3. Persentase penambahan semen portland dan serbuk batu bata pada campuran sebaiknya di lakukan penambahan agar memperoleh data hasil yang optimal.

4. Pengawasan intensif perlu dilakukan pada pelaksanaan pembuatan sampel di laboratorium dan juga perlu diperhatikan kondisi peralatan yang digunakan pada saat penelitian.

5. Hasil penelitian ini dapat digunakan sebagai acuan apabila ingin meneruskan atau mengembangkan penelitian ini

\section{DAFTAR PUSTAKA}

1. Dhowian, A W., and Edil, T B., 1980, Consolidation Behavior of Peats, Geotechnical Testing Journal,September, Philadelphia.

2. Bowles, Joseph E. Johan . Helnim. 1991. Sifat-sifat Fisis Geoteknis Tanah ( Mekanika Tanah ).PT. Erlangga. Jakarta.

3. Das, B. M. 1998. Mekanika Tanah (Prinsip-prinsip Rekayasa Geoteknik), Erlangga: Jakarta.

4. Hardiyatmo, Hary Christady. 1992. Mekanika Tanah 1. PT. Gramedia Pustaka Utama .Jakarta.

5. Hardiyatmo, Hary Christady. 2010. Stabilisasi Tanah Untuk Perkerasan Jalan. Gadjah Mada University Press. Yogyakarta.

6. Hardiyatmo, Hary Christady. 2012. Mekanika Tanah 1, Edisi Keenam. Gajah Mada University Press. Yogyakarta.

7. Sukirman, Silvia. 1999. Dasar-Dasar Perencanaan Geometrik Jalan. Bandung: Nova. 